\title{
EPHA2 Protein Overexpression
}

National Cancer Institute

\section{Source}

National Cancer Institute. EPHA2 Protein Overexpression. NCI Thesaurus. Code C131065.

A molecular abnormality indicating the presence of an abnormally high level of the ephrin type-A receptor 2 protein. 